\title{
Occupational therapy students' experiences and perceptions of culture during fieldwork education
}

\author{
Inge Sonn, B Sc OT (UWC), M OT (SU) \\ Associate Lecturer, Department of Occupational Therapy, University of the Western Cape
}

Nikki Vermeulen, B Sc OT (UWC), M Sc OT (UWC)

Associate Lecturer, Department of Occupational Therapy, University of the Western Cape

Background: Understanding a client's culture allows practitioners to consider the planning of intervention and allows for a client centred approach to be provided. During fieldwork education occupational therapy students can face the challenge of other cultural practices, standards, morals and ways of life coming into conflict with their own.

Purpose: There is minimal South African literature discussing the challenges and supporting factors that assist students in becoming culturally competent across cross-cultural settings. This article explored occupational therapy students' experiences of culture, and their perceptions of the barriers and enablers that culture presents during fieldwork education.

Methods: A qualitative study was conducted with undergraduate occupational therapy students from a university in Cape Town, South Africa. Data were collected using focus groups with each group of students from first to fourth year and were analysed using thematic analysis.

Findings: The two main themes that emerged from the analysis, were: I) "Culture is easily defined but not easily described", which focuses on the students own understandings and interpretations of culture, and 2) "Is there no 'me' in OT?" which specifically describes students' experiences of culture during fieldwork practice.

Implications: The findings of this study questioned whether cultural competence is static but determined that exposure to, positive attitudes towards and self-reflection on culturally diverse experiences are the factors that contribute towards developing cultural competence in culturally diverse situations.

Key words: Occupational therapy; Students; Culture; Cultural Competence; Cultural Sensitivity; Acculturalization; Fieldwork Education

\section{INTRODUCTION}

Within occupational therapy fieldwork practice, culture provides occupational therapy students with an understanding of how people live in social groups ${ }^{\prime}$. If an individual's culture is well understood it allows for many factors to be considered when intervention for the individual is planned, by providing a client-centred approach and in turn, increasing the chances of a more successful outcome. The challenges faced by occupational therapy students however, is when other cultural practices, standards, morals and ways of life come into conflict with the culture that they are a part of. The question that then comes to mind is, can holistic interventions still be provided by students experiencing these challenges? Social circumstances in South Africa provide a platform for occupational therapy students during their fieldwork practice to be exposed to and interact with clients who are poverty-stricken as well as those that come from cross cultural backgrounds ${ }^{2}$. Buchanan and Cloete ${ }^{3}$ observed that most students who come from middle to upper middle class backgrounds have little exposure to the harsh realities of poverty. Despite this, students are still expected to provide competent interventions within their fieldwork practices that are not lessened or unrelated to the client's culture or context ${ }^{4}$.

The future growth of the occupational therapy profession is dependent on preparing occupational therapists ${ }^{5}$ who are capable of practicing in cross-cultural settings. Fieldwork practice forms an integral part of this process in preparing occupational therapists for work in culturally rich and diverse settings. According to Buchanan and Cloete ${ }^{3}$, fieldwork practice is defined as any type of practical work intended to deliver the feel of being a professional within the working environment. This helps prepare students for work in these diverse settings once they have graduated. Bonello ${ }^{6}$ states that for this reason fieldwork practice has been included in the occupational therapy curriculum for the last century.

Fieldwork practice is the most ideal method to educate and prepare students to work in cross-cultural settings which await them once they are qualified therapists ${ }^{3}$. There is however minimal literature within the South African context exploring occupational therapy students' experiences of culture during various stages of their learning during fieldwork practice. Inclusive within this dearth of South African literature is evidence that highlights the supporting factors that assist students in becoming cross-culturally competent and, as a result, providing holistic client-centred interventions across these cross-cultural settings.

As such, this article focuses on occupational therapy students' experiences and perceptions of culture during their fieldwork practice. The objectives of the study were firstly to explore the occupational therapy students' experiences of culture, and secondly, to explore their perceptions of the barriers and enablers that culture presents during fieldwork practice. It was envisaged that the study could provide knowledge of the influence that culture may have on the learning and preparation required in becoming culturally competent as well as providing practical suggestions that could assist students to effectively deal with the implications of culture on their practical learning during fieldwork practice.

\section{LITERATURE REVIEW}

The literature review provides an overview of the concepts of culture and cultural competence, as well as the challenges related to developing cultural competence and various models that exist to 
frame its concepts and processes. In addition students' experiences of culture during fieldwork education are provided.

\section{Culture}

Ekelman et $\mathrm{al}^{7}$ view culture as a concept that is socially made up of an ever-changing awareness of how we view and interpret the world. Furthermore, culture enables people to relate to others as well as to the environment ${ }^{7}$. Culture encompasses standards, morals, principles, viewpoints, way of life and the learnt experiences that are shared by a group of people. It is also socially transmitted, and therefore is a representation of behaviour acquired through social learning. Culture is one of the significant factors that are ever-present in both the personal and professional beings. In other words, culture is "everywhere" and healthcare practitioners are expected to perform in a culturally diverse world ${ }^{8}$. The significance and understanding of culture is of paramount importance to the interactions between occupational therapists and their clients, as it provides a worldview of how people live socially and not simply as individual beings'.

Watson' suggests that occupational therapists are required to consider the interaction between the client's culture and their occupations. Based on the fact that occupations are driven by culture, providing culturally relevant intervention is central to upholding the client-centred focus of the profession. Bonder, Martin and Miracle 9 emphasise that in occupational therapy, occupational engagement is influenced by culture which impacts the occupations people choose to do as well as how they choose to do it. They further add that one's culture directly affects their participation in occupations. Thus by definition, in order to provide culturally relevant interventions, as occupational therapists we are required to have a client-centred focus to our interactions with our clients.

Culture can present with unique challenges to the occupational therapy practitioner, in which the occupational therapist's personal values, cultural disposition and role assumption may differ from the values of the clients as instilled by their cultural beliefs ${ }^{10}$. Additionally, an integral aspect of cultural diversity is dialect as it enables people to interpret, communicate and express personal points of view $^{\prime \prime}$. However, communication is still considered a challenge to this present day. Not being able to communicate directly with the clients due to dialect or language differences is a cultural factor that can be a barrier to attaining client-centredness ${ }^{3}$. It is important for the occupational therapist to be aware of and be sensitive to the influence that culture has on the success of intervention and services rendered. Therefore, it could be said that occupational therapy students should be culturally competent in order to provide effective interventions and quality of care through the selection and use of culturally relevant occupations that are meaningful and that align with the client's way of life.

\section{Models of cultural competence}

Dillard et al $^{12}$ defined cultural competence as a perception of, compassion toward and a comprehension of the meaning of culture. In addition, Park et $\mathrm{al}^{13}$, proposes that cultural competence is characterised by respect for dissimilarities, continuous self-reflection of viewpoints, attentiveness towards differences, on-going growth in cultural knowledge and adaptation to services rendered by occupational therapists. Our profession has recognised the need to be mindful and compassionate and understanding to cultural differences within occupational therapy practices ${ }^{14}$.

In developing cultural competence, Bennett's developmental model of intercultural sensitivity ${ }^{15}$ hypothesised a framework for conceptualising the dimensions of intercultural competence. Bennett posited that people move through six viewpoints, namely: (i) denial, (ii) defense reversal, (iii) minimisation, (iv)acceptance, (v) adaptation and (vi) integration. The first three viewpoints are conceptualised as ethnocentric, referring to one's own cultural experience as the focal point to reality ${ }^{14}$ The second three viewpoints are theorised as ethnorelative, referring to one's own culture being experienced in the context of other cultures. With this framework,
Bennett and Wiseman ${ }^{16}$ anticipated that people would reach the stage of acceptance, which is a state where one's own culture is accepted and experienced as just one of the many intricate worldviews on culture.

Darawsheh, Chard and Ehklund ${ }^{17}$ questioned whether practicing in a client-centred manner also allows the practitioner to be culturally competent at the same time. Their study that aimed to investigate the process, stages, and characteristics required for cultural competency, found that it is not enough for a practitioner to be only client-centred - as they may well be able to design an intervention that addresses the clients' needs - but might not be culturally ready to work with that culturally diverse client. This study by Darawsheh, et $\mathrm{a}^{17}$ was undertaken due to limited literature available on the process of developing cultural competency. As such they developed a model of cultural competency based on the premise that cultural competency is a process of cultural maturity comprised of a series of stages where cultural competence represents the end point of the process ${ }^{18}$. The model suggests six stages to the process of cultural competency. These stages, cultural awareness, cultural preparedness, the cultural picture of the person, cultural responsiveness, cultural readiness, and cultural competence, will be elaborated on in the discussion section.

\section{Students experiences of culture in fieldwork education}

Forwell, Whitefore and Dyck ${ }^{19}$ undertook a twin study between two occupational therapy programmes in Canada and New Zealand. Even though the two occupational therapy programmes are similar, the curricular differences are based on the socio-political content of the countries. Therefore, because the cohorts of students have differing demographic profiles in the twin study, it can be assumed to be similar to the South African cohort of occupational therapy students. The motivation for conducting their study was driven by the following questions: Is occupational therapy practice sensitive to and do they have enough awareness of the cultural differences in determining and managing health, illness and disability? Are occupational therapists receiving adequate education to deal with diverse and complex cultural differences as it has a direct impact on their practice?

The results of their study yielded a strong need from the students to receive more education on the do's and don'ts of different cultural groups. This is mainly due to the fact that students tend to struggle with concepts related to ethnicity, race, culture and cultural differences. The students of this study also pointed out that the development of a deeper understanding and appreciation of cultural differences needs to happen over time and be linked to their clinical skills development. This implies that there is a strong desire for students to be culturally competent practitioners. The study also revealed that more research needs to be done to provide clearer educational and professional standards in this ever-changing day and age.

\section{METHOD}

This study followed a qualitative research methodological approach with an exploratory descriptive design. An explorative design is used to gather narratives of experiences within the topic and to gain a full understanding of the participant's views ${ }^{20}$. This allowed for an understanding of the subjective meanings of the perceptions and experiences of culture during fieldwork practice among occupational therapy students ${ }^{21}$. The study was conducted with undergraduate occupational therapy students from a university in Cape Town, South Africa. In the four year undergraduate occupational therapy programme offered at this university, students are required to complete 1000 hours in fieldwork practice before they can qualify as an Occupational Therapist ${ }^{22}$. This therefore affords an opportunity for all students to be exposed to a variety of culturally-diverse fieldwork placements.

Ethical clearance for the study was obtained through the Research Ethics Committee of the University of the Western Cape and 
permission was granted by the Head of the Occupational Therapy Department at the University of the Western Cape to conduct the study. Consent from the participants was obtained using an information sheet and written consent forms. The participants were made aware that participation in the study was voluntary, they could withdraw at any point without any consequences, and that confidentiality would be upheld at all times.

Purposive sampling was used in the recruitment of five participants from each cohort of students. Students from first to fourth year were considered as participants so that a range of fieldwork experiences from fieldwork visits on a first year level to fieldwork practice on a fourth year level could be incorporated into the study. Including students across all four years of study allowed the researchers to gauge the students' experiences of culture through fieldwork visits for interactive purposes on a first year level through to the provision of intervention on a fourth year level. The selection of the five participants from each cohort of students ensured that each participant was from different racial, cultural and religious backgrounds; ensuring that the sample of participants were representative of the South African population.

Data were collected through a focus group with each of the cohorts of students which was facilitated by the researchers. Semi-structured questions were formulated with the aim to ease responses, build the participants confidence and establish rapport ${ }^{23}$. Questions focused on the participants' understanding of culture and how they identified their own cultures personally, and extended to their perceptions of the role of culture in a professional context. The researchers also explored the participants' understanding of professional identity and their perceptions of whether culture could impact on its development. As part of the data analysis stage, all focus groups were audio-taped and transcribed verbatim. The process of thematic analysis ${ }^{24}$ was used to analyse the data and examine similarities between concepts and ideas by means of coding. The coded data were then grouped into categories which allowed the researchers to form themes within the research. Trustworthiness was ensured through applying the constructs of credibility, transferability dependability and confirmability ${ }^{25}$ through the use of data triangulation, the specific sampling strategy of purposeful sampling, the use of an audit trail and researcher reflexivity.

\section{FINDINGS}

The findings of the study is discussed by highlighting data gathered from the focus groups facilitated with the first to fourth year undergraduate occupational therapy students. The findings of this study form part of a greater research study conducted by final year undergraduate students as part of their research module. As such only two of the main themes, which emphasise the students' experiences and perceptions of culture during fieldwork education, will be discussed.

\section{"Culture is easily defined but not easily described"}

The theme "Culture is easily defined but not easily described", discusses the students' personal understandings of culture and aspects of culture that they found assisted or hindered progress in fieldwork education.

\section{Understanding of culture}

The diversity of the population of South Africa was recognised as an asset by the participants of this study when they acknowledged that being different was considered to be 'normal' in this country. The students' highlighted that in their classes alone they were exposed to a diverse range of cultures and felt that this single-handedly was the foundation of being able to work with people who were different to them. They also valued the extent of their exposure to diverse cultures within the course and felt that culture plays a big role within any health profession.

If you could just see now in our class, like the diversity of culture there, it's like huge. (Participant A5, I ${ }^{\text {st }}$ year student)
The students understood culture to be comprised of one's values, roles and responsibilities, and felt that this is what made them who they are. In addition they also included religion, race and nationality as aspects that were incorporated into the concept of culture. The students however agreed that usually one of these aspects is more prominent than the rest in one's life in that they tended to define their culture by race (e.g. Xhosa) or religion (e.g. Islam). The students expressed though that they found it challenging to assign one term to their culture because who they are and what made them who they are, are complex constructs that are ever-changing; made up and influenced by one's own interests and experiences. The general consensus by the students however was that cultures exist not only in people but in places and that as they move through life they would be immersed in and exposed to various cultures. This immersion and exposure they express allow one's own culture to be adaptable to different environments, situations and experiences and as such not 'set in stone'.

We were saying that it's broad and that there's so many different cultures, how can we put ourselves into one? There's a culture as the UWC students, but there's a culture as the OT student and there's a culture at home, with friends, all of that. (Participant $\mathrm{C} 2,3^{\text {rd }}$ year student)

The students also agreed that due to the consistent immersion in the culture that exists in the occupational therapy programme, over time their own culture expanded to include aspects of occupational therapy. The students stated that occupational therapy itself became a part of who they are and contributed towards what made them who they are. In essence occupational therapy became a part of their culture.

Wherever you go your own culture changes. When I came to OT it changed, its (OT) a lot of who I am and makes up what I believe in and plays a big role. (Participant D4, $4^{\text {th }}$ year student)

\section{Positive and negative aspects of culture}

Some students felt that certain aspects of culture such as language, race and religion positively influenced their ability to relate to their clients. One student described how her physical appearance (based on her religion) allowed her client to immediately identify and relate to her and vice versa. Another student described how being able to understand and communicate in isiXhosa (one of the national languages of South Africa) was an advantage during fieldwork practice as it assisted in the interaction and intervention with her client. Language in general was expressed by the students to be a cultural factor that allowed them to be more adaptable during fieldwork practice.

It has given me that adaptability, being able to speak two languages (Participant DI, $4^{\text {th }}$ year student)

Interestingly, other students felt that the aspects of language, race and religion within culture negatively impacted on their ability to relate to and provide intervention for their clients. The Muslim students shared their common experiences where they acknowledge that their religious beliefs impacted on their ability to provide their clients with the best possible intervention. One student shared how according to Islamic religion she is not permitted to be alone with a man unless it is her husband and as a result made sure that all her interactions with her male client were in a public space. This, she felt impacted on the ability to establish a proper client-therapist relationship and ultimately disadvantaged her as a therapist. Other students shared that within the African culture it was considered disrespectful to look someone older than you directly in the eyes and felt that this also negatively impacted on their ability to build an interpersonal relationship and provide adequate intervention for their clients.

..ifI'm to speak to someone that's from another African culture, and I do that (look them in the eye when speaking to them), they will see it as being pretty much rude to them." (Participant $\mathrm{Cl}, 3^{\text {rd }}$ year student) 
Collectively students felt that regardless of the positive or negative experiences of culture during fieldwork practice, it was their responsibility as health professionals to learn about and come to understand their client's culture in order to provide the best intervention possible.

From an occupational therapy point of view you kind of need to tap into their culture; you need to understand what it is and who they are in terms of their culture. (Participant A5, I ${ }^{\text {st }}$ year student)

\section{"Is there no 'me' in OT??"}

The second theme "Is there no 'me' in OT?" discusses factors surrounding culture that students felt influenced their professional development. Also highlighted in this theme are the students experiences of having to "put on an OT mask" when working with clients to hide their own cultural identities.

\section{Conflicting cultures}

The findings of the study highlighted a distinct difference between the junior (first to third year) and senior (fourth year) students opinions regarding their ability to not allow their own culture to come into conflict with their client's culture. The first to third year students expressed the view that disregarding their own culture for the benefit of the client was not an issue as this is what it meant to be an occupational therapist. The students felt that they are in a profession that focuses solely on the needs of the client and as such needed to disregard their own ways of practice and conform to that of another culture as a result of the expectations of the profession.

You have to put aside your own personal feelings and treat the client, because at the end of the day it's about them and not about you. (Participant B5, $2^{\text {nd }}$ year student)

In contrast to this however, the final year students, possibly due to their increased exposure to fieldwork practice, described a slightly more complex view to disregarding one's own culture. These students discussed that occupational therapy practice is not as straightforward as always being able to put what is meaningful to one's client first when it comes into conflict with their own values and beliefs. In general the students felt that flexibility and compromise is an important part of being client-centred, but stated that it was also necessary to be realistic in selecting culturally relevant interventions that do not compromise the clients or the therapists' values or beliefs.

I think you need to be flexible within your own culture and understanding of the other culture as well, you need to compromise, but then at the same time you need to be realistic. (Participant D5, $4^{\text {th }}$ year student)

\section{Culture and professionalism}

Due to the client-centred nature of the profession, the students started referring to the professional face that one wears when practicing, as an 'OT mask'. This 'OT mask' was described as one of the ways in which students cover up any feelings or emotions evoked by their clients' cultures or beliefs that come into conflict with their own. Students explain that the wearing of the 'OT mask' initially feels like having two distinctly different personalities and lifestyles but that as time goes by it eventually becomes the norm. The students describe that eventually occupational therapy becomes a part of their personalities and lifestyle as they feel that this is part of the process of becoming one with the culture of the profession.

Because basically it's like when you are an OT you're wearing a mask and your lifestyle has to merge with your practice and your personal life becoming one. In the beginning it felt like I have to put a mask over my personal life and my culture. (Participant B2, $2^{\text {nd }}$ year student)

The findings of the study highlight the students' suggestion that the concepts of exposure, reflection and attitude are aspects that could assist in the "acculturalisation" process of becoming an occupational therapist. In this context "acculturalisation" is a description of the numerous, gradual and long-term processes required in response to the cultural changes in our client-base and environment.
The students in this study share that being willing to be exposed to different cultures allows levels of confidence and comfort to grow in interacting with clients of various cultures. One of the first year students in this study felt that exposure is beneficial as a means of overcoming one's personal constructs of culture and would be valuable when in a situation where the surrounding culture is different to your own. A final year student expressed how exposure allowed for experiences to occur and learning opportunities to arise from those experiences, resulting in the ability to effectively deal with issues that may have arisen when working with clients from different cultures.

I think, experience is the best teacher, I don't think my views would have been the same had you guys had this focus group in Ist year with me. (Participant D2, $4^{\text {th }}$ year student)

Even though the students felt that through exposure came experience, they also felt that experience brings with it critical incidents which can then be reflected upon for further learning. The students expressed that the occupational therapy programme has a strong focus on reflective practice and self-reflection and this process is what allowed them to deal with and learn from their cultural experiences within fieldwork practice.

Ultimately, regardless of the exposure or the experiences provided during the occupational therapy programme, the students believed that the greatest determining factor to being a culturally considerate occupational therapist is one's attitude towards cultural situations. The students highlight that the challenge is not based on the struggle between different cultures, but it is based on the attitudes towards different cultures. In this regard the students felt that being open to accumulating knowledge and experiencing various cultures is the basis of "acculturalisation" and the provision of client-centred interventions.

It's your attitude that influences this entire thing. You need to know your clients culture, as well as your own... (Participant AI, I ${ }^{\text {st }}$ year student)

\section{DISCUSSION}

The aim of this study was to explore and understand occupational therapy students' experiences and perceptions of culture during their fieldwork practice. The significance of this study lay in the hope that it would provide knowledge and suggestions that could assist students during the process of 'acculturalisation' in becoming an occupational therapist. This research study provides information on the challenges that culture presents in client-centred practice and a description of the students' perceptions on the aspects of exposure, reflection and attitude that could act as enablers in ensuring relevant occupation-based interventions across cross-cultural settings.

Ripat, Wener and Dobinson ${ }^{26}$ state that the core concepts central to client-centred practice is that of developing effective partnerships and collaborations with clients through effective communication; promoting shared decision making; respecting diversity and holism; recognising power in relationships, and ways to realign power; and providing contextually congruent occupational therapy services. The findings of this study show however that some of the challenges experienced by students in cross-cultural settings in their fieldwork practice can present as barriers to attaining the aforementioned qualities of client-centred practice. One such example was the language barriers experienced by students in communicating with their clients, which hindered effective client-centred practice.

The six stages suggested by Darawsheh, et. al. ${ }^{17}$ were used to highlight the enablers and barriers that students in this study experienced in the process of 'acculturalisation' towards becoming culturally competent client-centred practitioners. Cultural awareness, the first stage in the process, is defined as an awareness of one's own culture as well as being able to recognise differences within other cultures. Hammell ${ }^{27}$ supports this definition by adding that cultural awareness requires an awareness of one's own assumptions, beliefs, values, and biases; an understanding of how these views might differ from others; being conscious of the impact 
of one's own cultural identity on one's professional practices; as well as the ability to implement culturally appropriate intervention strategies. As reported in the findings of this study, the students emphasised that your attitude towards understanding different cultures and towards cultural diversity could have a great influence on your ability to engage with your clients. Students in this study expressed that the barrier is not the actual cultural difference but one's attitude toward it. Therefore, the process of becoming culturally aware requires professionals to adopt an attitude of openness towards, observation of, and recognition about the differences that exist between your own culture and that of your clients. Knowing oneself is vital to this process and as such it is important that professionals (students and qualified therapists), are encouraged to critically examine how their own cultures, behaviours and actions could impact on their interactions with their clients.

Cultural preparedness, the second stage in the process, talks to ones feelings of preparedness to engage in cross-cultural settings. This is generally determined by the amount of exposure to culturally diverse settings in which professionals are able to acquire the necessary experience and knowledge needed ${ }^{17}$. This exposure also allows professionals to develop confidence, preparing them to face unexpected situations. Exposure, one of the suggestions made by the students in this study, was emphasised as an important factor in gaining experience in working with clients from diverse cultures in order to learn how to effectively deal with issues that may arise from working with culturally diverse clients. Exposure was effectively what allowed students to be prepared to engage in cross-cultural settings. This however varied as students at different year levels expressed varying degrees of preparedness with the more senior students feeling more prepared due to more fieldwork exposure. Darawsheh, et. al. ${ }^{17}$ state that such exposure may be used as a strategy for promoting cultural competency as long as it leads to awareness about cultural differences as well as preparedness to encounter them. As such occupational therapy programmes are encouraged to provide their students in all levels of study with increased opportunities for engagement in culturally diverse settings as well as for developing learning and self-reflective opportunities based on these experiences. Occupational therapy educators should include opportunities for sharing and discussing cultural differences as part of class activities as an additional method of developing cultural preparedness.

The third stage of a cultural picture of the person is described as the ability to view a client through a cultural lens in attempting to understand the clients' world. Suarez-Balcazar and Rodakowski ${ }^{28}$ emphasise the importance of this stage stating that in order for professionals to practice in a client-centred manner, understanding the individual and cultural needs of the client is important. Darawsheh, et. al. ${ }^{17}$ state that in order to master this stage professionals are required to enter into any setting without any preconceived notions. They add that being able to engage with clients while having a blank mind-set allows for feelings of confidence and as a result, the increased ability to be more prepared for cultural differences and unknown situations. The students in this study felt that it was up to them as professionals to "tap" into their clients' culture by putting their own culture aside in order to fully understand who their client was. Muñoz ${ }^{18}$ indicates that in order to recognise cultural differences, the skills of active, culturally relevant assessments and observations focussed on culturally relevant tasks and roles are required. Iwama ${ }^{29}$ however criticised the assessments and models used in occupational therapy stating that most have been developed and designed from a Western world view making them not always applicable our South African context. It is for this reason that occupational therapy departments and education programmes are encouraged to research, develop and include into their practice and curricula, assessment and observational criteria that are culturally and contextually relevant which could enhance the skills, strategies and abilities of students and practitioners to be able to capture a culturally relevant individual portrait of each client.

The fourth and fifth stages of the process of cultural compe- tency are the ones that students in this study struggled with most. According to Muñoz ${ }^{18}$, cultural responsiveness (stage four) requires therapists to implement interventions that are culturally specific while at the same time maintaining their own integrity without violating their own cultural values. Here the students expressed having to wear what they called an "OT Mask" which allowed them to hide behind any discomfort evoked by culturally diverse situations. The students also strongly felt that it was their duty to not allow their culture to come into conflict with that of their clients. Cultural readiness (stage five) similarly states that therapists then have the potential to deliver on culturally relevant practice while considering both the clients cultural differences and the way in which these interventions are carried out without compromising their own cultural integrity ${ }^{17}$. The more senior students in this study realised that it was important to be flexible and realistic when dealing with culturally diverse situations but at the same time maintain professional boundaries and develop strategies to not compromise the clients level of care. In order to achieve both stages four and five, students would be required to be fully aware of and develop the ability to continually assess their own attitudes and preferences towards cultural differences. For the students in this study this is where reflective practice and self-reflection acted as a platform to critically analyse and assess their own assumptions, beliefs, values, and biases and develop an understanding of how their own perspectives differed from those of their clients. Kinsella ${ }^{30}$ believes that in order for professionals to transform and develop, they need to balance the union of reflection and action and more importantly to work from this position as occupational therapists. In her work on reflective practice, Kinsella ${ }^{30}$ highlights six considerations as a way for therapists to think about and develop as reflective practitioners. The fourth consideration named 'exploring assumptions' is important to do on a regular basis as it will allow professionals to recognise how it influences practice. As such it is important for occupational therapy education programs and independent practitioners to increase the platform for reflective practice in cultural diversity as this type of reflection has the potential to raise self-awareness allowing professionals to understand their behaviours in practice.

The last stage of cultural competency is described by Darawsheh, et al ${ }^{17: 16}$ as "a process where therapists have a clear appreciation of their own cultural identity and a deep understanding of cultural differences that enables them to respond effectively when working with those from cultural backgrounds the same as and different from their own". Lindsay et $\mathrm{al}^{31}$ adds that in order to provide culturally competent practice, special strategies and skills should be used that include and integrate all clients within services regardless of their cultural backgrounds. The students in this study displayed various aspects of reaching cultural competency but never a collective that met the full description of cultural competence. Considering that each client we encounter is unique it can therefore be questioned whether the concept of cultural competence is static or whether it needs to be attained for each client we meet. The findings of this study indicate however that increased levels of exposure to, increased positive attitude towards and increased ability to reflect on culturally diverse experiences are factors that contribute towards developing cultural competence in culturally diverse situations.

\section{CONCLUSION}

The process of 'acculturalisation' in occupational therapy is a complex issue that is important and relevant in education, practice, and research. This study explored first to fourth year occupational therapy student's experiences of culture and their perceptions of the barriers and enablers that culture presents during fieldwork practice. Students expressed how aspects such as language, race and religion acted as both enablers and barriers to client-centred practice but also shared how the profession of occupational therapy has its own culture which eventually becomes a part of who the student is. Based on these students' experiences and perceptions, the findings of the study show that exposure to cross-cultural set- 
tings and experiences, reflection based on these experiences and a positive attitude towards different cultures are aspects that can facilitate the process of 'acculturalisation' for students.

Students and practitioners need to be guided to immerse themselves in, and reflectively engage in culturally diverse situations. Occupational therapy education programmes need to enhance their focus on cultural diversity so that students are able to not only understand the theories behind cultural competence but also develop the skills and strategies required to be culturally prepared to engage in culturally diverse settings. In order to accommodate increasing diversity, improve the quality of care provided to our clients, and increase client compliance and satisfaction within the outcomes of intervention ${ }^{32}$, it is in the best interest of occupational therapy professionals to strive for cultural competence. Luckily, cultural competence is an on-going ride as opposed to an end or destination that is assisted by exposure, reflection and a willingness to learn.

\section{ACKNOWLEDGEMENTS}

This paper is based on an undergraduate research report undertaken by final year students in 2014 at the Occupational Therapy Department at the University of the Western Cape, South Africa. The authors of this paper would like to acknowledge the four researchers of this study, Ni-Shaat Jacobs, Tracey-Lynne Jacobs; Jude Layman and Lauren-Lee Truter.

\section{REFERENCES}

I. Watson, R.M. Being before doing: The cultural identity (essence) of occupational therapy. Australian Occupational Therapy Journal. 2006; 53: $151-158$

2. Health Professionals Council of South Africa. Continued Professional Guidance: Guidelines for Health Professionals. 2009.

3. Buchanan $\mathrm{H}$, Cloete L. Preparing students for the complexities of practice learning, In: Lorenzo T, Duncan M, Buchanan H, Alsop $A$, editors. Practice and service learning in Occupational Therapy. Enhancing potential on context. Sussex: Whurr; 2006:73-87.

4. Fourie M, Galvaan R, Beeton $\mathrm{H}$. The impact of poverty: potential lost. In Watson R, Swartz L, editors. Transformation through occupation. London: Whurr; 2004:30-40.

5. Gray M, Clark M, Penman M, Smith J, Bell J, Thomas Y, TrevanHawke J. New graduate occupational therapists feelings of preparedness for practice in Australia and Aotearoa/New Zealand. Australian Occupational Therapy Journal. 2012; 59(6): 445-55.

6. Bonello M. Perceptions of fieldwork education in Malta: Challenges and opportunities. Occupational Therapy International. 200 I; 8(I): 17-33.

7. Ekelman B, Delballo-Haas VD, Bazyk J, Bazyk S. Developing Cultural competence in occupational therapy and physical therapy education: a field immersion approach. Journal of Allied Health. 2003; 32(2): |3|-|37.

8. Beach MC, Price EG, Gary TL, Robinson KA, Gozu A, Palacio A, Smarth C, Jenckes MW, Feuerstein C, Bass EB, Powe NR, Cooper L.A. Cultural Competency: A systematic Review of Health Care Provider Educational Interventions. Med Care. 2005; 43(4): 356373.

9. Bonder BR, Martin L, Miracle AW. Culture Emergent in Occupation. American Journal of Occupational Therapy. 2004; 58:159-168.

10. Iwama MK. Meaning and Inclusion: Revisiting culture in occupational therapy. Australian Occupational Therapy Journal. 2004; 5 I (I): I-2.

II. Murden R, Norman A, Ross J, Sturdivant E, Kedia M and Shah S. Occupational therapy students' perceptions of their cultural awareness and competency. Occupational Therapy International. 2008; I5 (3): $19 \mid-203$.

12. Dillard M, Andonian L, Flores O, Lai L, MacRae A, Shahir M. Culturally competent occupational therapy in a diverse populated mental health setting. American Journal of Occupational therapy. 1992; 46(8): $721-726$

13. Park ER, Betancourt JR, Kim MK, Maina AW, Blumenthal D, Weissman JS. Mixed messages: residents' experiences learning crosscultural care. Academic Medicine. 2005; 80(9): 874 - 880.

14. Odawara E. Cultural competency in occupational therapy: beyond a cross-cultural view of practice. American Journal of Occupational Therapy. 2005; 59(3): 325-334.

15. Bennett, M.J. Towards ethnorelativism: A developmental model of intercultural sensitivity. Education for the Intercultural Experience. Ed. R.M. Paige. 2nd edition. Yarmouth, ME: Intercultural Press; 1993: $21-71$.

16. Hammer MR, Bennett MJ, Wiseman R. Measuring intercultural sensitivity: The intercultural development inventory. International Journal of Intercultural Relations. 2003; 27(4): 42I-443.

17. Darawsheh W, Chard G, Eklund M. The Challenge of Cultural Competency in the Multicultural $2 \mathrm{I}^{\text {st }}$ Century: A Conceptual Model to Guide Occupational Therapy Practice. The Open Journal of Occupational Therapy. 20I5; 3(2).

18. Muñoz JP. Culturally Responsive Caring In Occupational Therapy. Occupational Therapy International. 2007; 14(4): 256-280.

19. Forwell SJ, Whiteford G, Dyck I. Cultural competence in New Zealand and Canada: Occupational therapy students' reflections on class and fieldwork curriculum. Canadian Journal of Occupational Therapy. 200I; 68(2): 90-103.

20. Magilvy J, Thomas E. A First Qualitative Project: Qualitative Descriptive Design for Novice Researchers. Journal for Specialists in Paediatric Nursing. 2009; 14(4): 298-300.

21. Goldkuhl G. Pragmatism vs interpretivism in qualitative information systems research. European Journal of Information Systems. 20I2; 2I(2): I35-I 46.

22. World Federation of Occupational Therapists (WFOT). Revised minimum standards for the education of occupational therapists. The Council of the World Federation of Occupational Therapists. 2002.

23. Gill P, Stewart K, Treasure E, Chadwick B. Methods of Data Collection in Qualitative Research: Interviews and Focus Groups. British Dental Journal. 2008; 204:29I-295.

24. Braun V, Clarke V. Using thematic analysis in psychology. Qualitative Research in Psychology. 2006; 3: 77-10I.

25. Lincoln Y S, Guba EG. Naturalistic inquiry. Beverly Hills, CA: Sage; 1985.

26. Ripat J, Wener P, Dobinson K. The Development of Clientcentredness in Student Occupational Therapists. British Journal of Occupational Therapy. 2013; 76(5): 217-224.

27. Hammell KR. Occupation, well-being, and culture: Theory and cultural humility. Canadian Journal of Occupational Therapy. 2013; 80(4): 224-234.

28. Suarez-Balcazar Y, Rodakowski J. Becoming a culturally competent occupational therapy practitioner: Practical ways to increase cultural competence. OT Practice. 2007; I2(I7): I4- 17.

29. Iwama M. Towards culturally relevant epistemologies in occupational therapy. American Journal of Occupational Therapy. 2003; 57(5): 582-588.

30. Kinsella EA. Reflections on reflective practice. Canadian Journal of Occupational Therapy. 200I; 68(3): 195-198.

3I. Lindsay S, Tétrault S, Desmaris C, King GA, Piérart G. The cultural brokerage work of occupational therapists in providing culturally sensitive care. Canadian Journal of Occupational Therapy. 2014; 8I(2): II4-I23.

32. Flecky K, Gitlow L. Service-learning in occupational therapy education: Philosophy and practice. Boston, MA: Jones and Bartlett; 20II.

\section{Corresponding Author}

Inge Sonn

E-mail: isonn@uwc.ac.za 